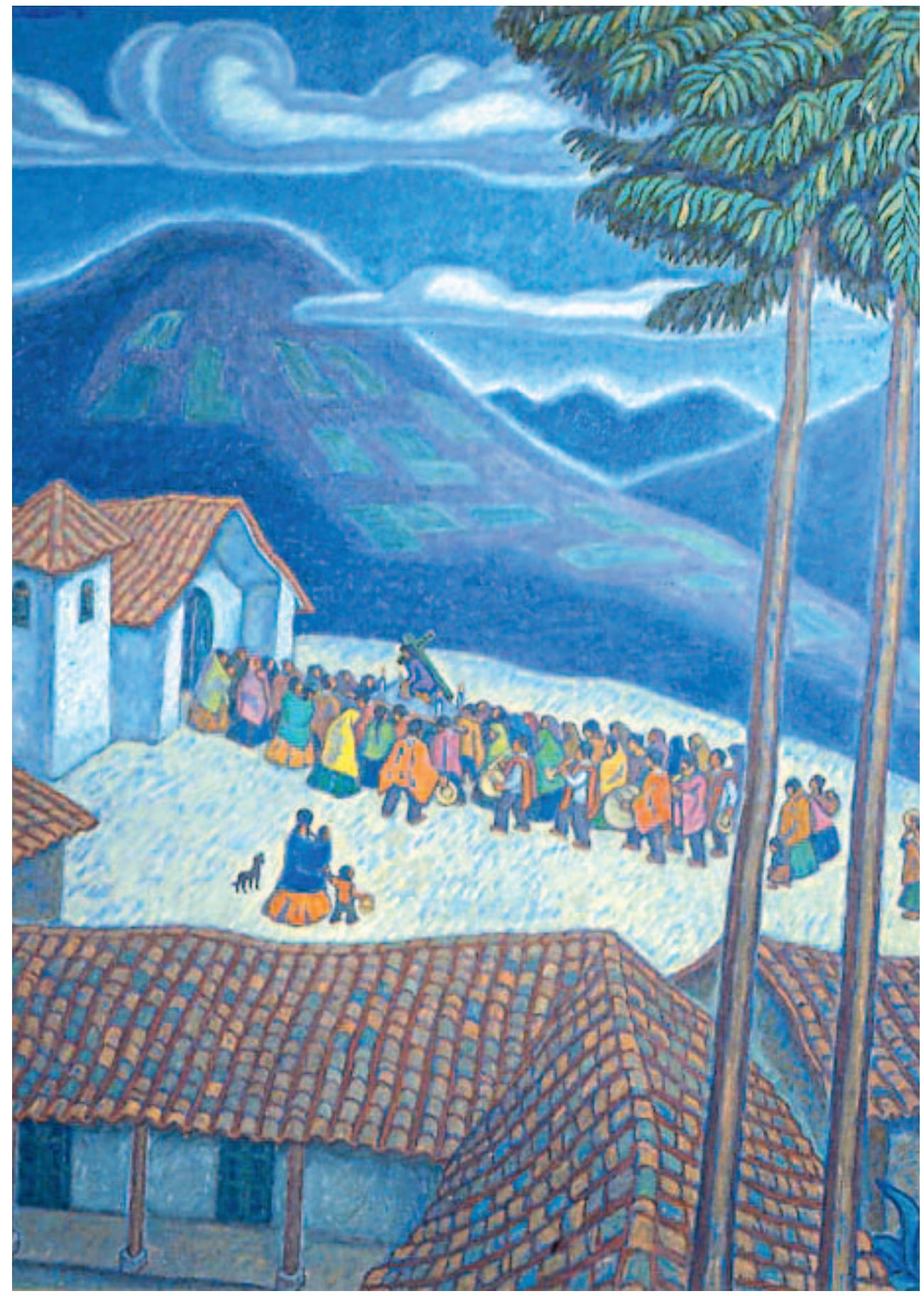

La procesión. Camilo Blas. 


\title{
Dos francotiradores de la crítica
}

\author{
Alfonso Castrillón Vizcarra \\ Caperucita Roja: iAbuelita, abuelita. \\ Qué ojos tan grandes tienes! \\ El Lobo Feroz: iPara mirarte mejor! \\ Charles Perrault, Caperucita Roja.
}

Un tema interesante de la Historia de la Crítica de Arte en el Perú es el de la adopción de términos y teorías que han surgido más allá del continente y que se han aplicado con éxito en nuestro medio. Uno es, sin duda, el termino "fortuna" que en la crítica de arte puede significar la suerte (o el infortunio) que han tenido ciertos estilos, artistas y teorías, juzgados por sus contemporáneos. Hasta donde he podido averiguar el término lo utilizó Giovanni Previtali en su libro La fortuna dei primitivi, dal Vasari ai neoclassici (Torino, 1964), trabajo que inaugura una etapa en los estudios artísticos ya que va más allá del tradicional encuadre historicista para hurgar en la vida social y en las arenas movedizas del gusto del público y su relación con los artistas y el arte.

En nuestro medio Luis Eduardo Wuffarden, en su introducción al libro sobre Sérvulo Gutiérrez ${ }^{1}$, ha empleado la locución "fortuna crítica” en relación a la actitud que asume el periodismo en la formación del mito del pintor iqueño, como el juicio de algunos críticos de la época.

Pero no es a la invención de Previtali que queremos dedicar este artículo sino a la "fortuna" que ha tenido en nuestro medio el aforismo de Maurice Denis ${ }^{2}$ que reza:

“Se rappeler qu'un tableau -avant s'être un cheval de bataille, une femme nue, ou quelconque anecdote- est essentialment une surface plane recouverte de couleurs en un certain ordre assamblées". ${ }^{3}$

A primera vista este pequeño texto nos lleva a pensar en el materismo de la pintura de Fautrier (París1898-1964), en el concretismo de la pintura-pintura que terminó en el expresionismo abstracto norteamericano. Pero no es así. El aforismo de Denis no pretende ser predictivo y solo quiere hacer reflexionar sobre la superación del Impresionismo hacia una economía formal lograda con un dibujo ajustado, el uso del color de una manera subjetiva y la importancia de un fermento espiritualista, como ejemplifican sus propias pinturas. El "antes de ser un caballo de batalla, una mujer desnuda o cualquier anécdota" no quiere decir la proscripción del tema sino, a mi modo de ver, la valoración de "otros temas" que irían desde el misticismo de Denis hasta los interiores de Vuillard y Bonnard, donde se privilegia la "superficie plana recubierta de colores juntados en un cierto orden”, es decir la exaltación de los "valores plásticos".

1 Wuffarden, Luis Eduardo, “Entre los límites de la modernidad, Sérvulo Gutiérrez y la generación de los “Independientes”, en Sérvulo Gutiérrez 1914-1961, edición Telefónica-Museo de Arte de Lima, 1998.

2 Maurice Denis (Granville 1870-París 1943) perteneciente al grupo Nabis, amigo de Gauguin, Sérussier, escribió sus 24 aforismos bajo el título de "Le Symbolisme", en Art et critique, 23-30 de octubre de 1890.

3 "Acordarse que un cuadro -antes de ser un caballo de batalla, una mujer desnuda, o cualquier anécdota- es esencialmente una superficie plana recubierta de colores juntados en un cierto orden”. 
En la Lima de los años 40, que por entonces tenía unos 800.000 habitantes, ejercieron la crítica de arte, habitualmente, hombres como Carlos Raygada, Emilio Delboy, Manuel Solari Swayne, Sebastián Salazar Bondy, entre los más conocidos. Pero también, ocasionalmente, escribieron sobre el arte del momento, dentro de la categoría de los "francotiradores"4, Juan Ríos Rey (poeta y dramaturgo) y Raúl María Pereira hijo, (diplomático). El primero publicó, bajo el seudónimo de Hans Valdemar, "Los pintores Independientes" en el periódico Trinchera Aliada, en 1940, y el segundo "Ensayo sobre la Pintura Peruana Contemporánea" en la revista El Arquitecto Peruano, en junio de 1942, trabajo que se convertiría en su tesis de Bachiller en 1944. Años más tarde Juan Ríos publicó La pintura contemporánea en el Perú, libro editado por Cultura Antártica en 1946.

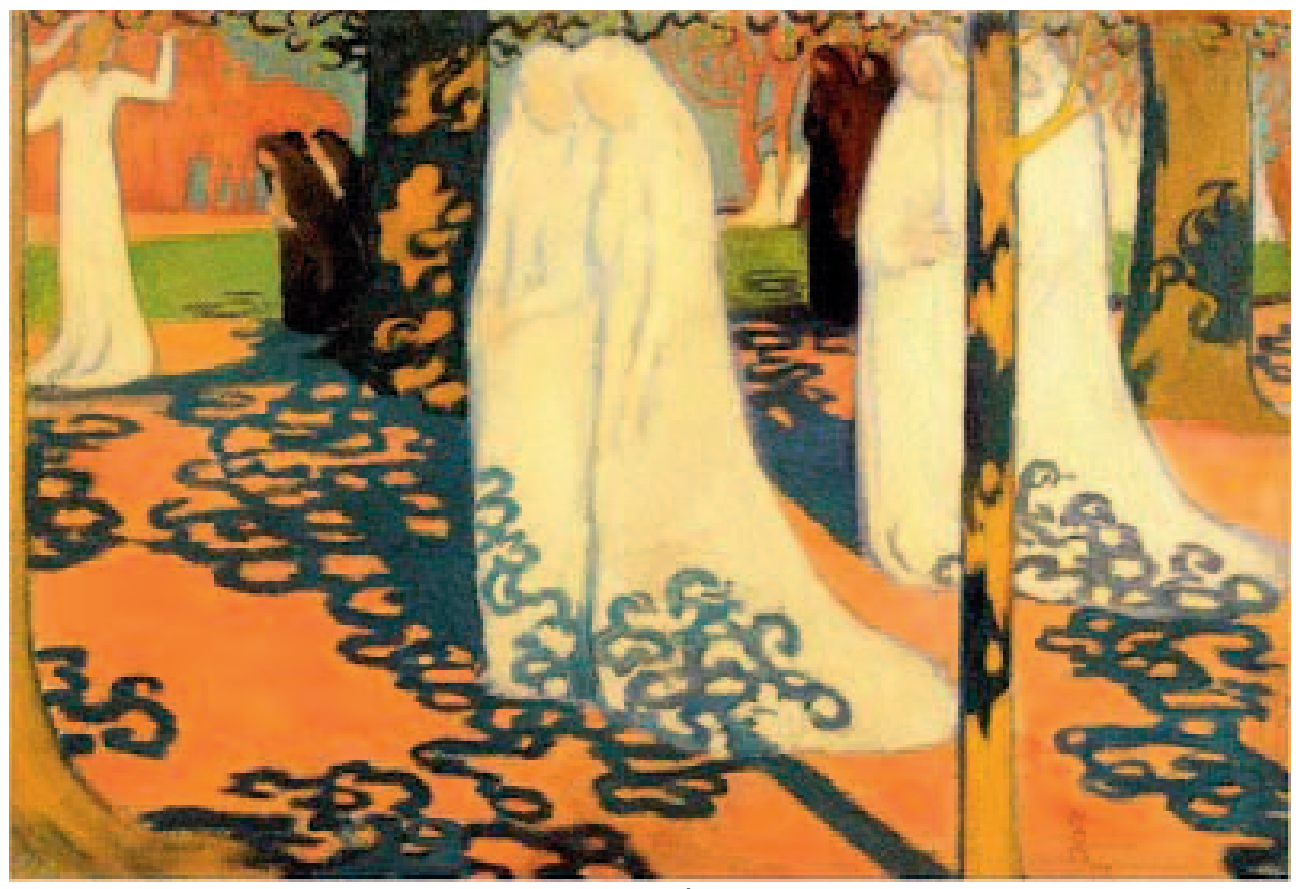

Procesión bajo los árboles. Maurice Denis, 1892. Óleo sobre tela, 56 x $81 \mathrm{~cm}$. (C) APSAV.

Juan Ríos, en su artículo de 1940, es el primero -creo- en citar a Denis, interpretándolo en el sentido de que si es importante el tema lo son más "los valores plásticos", el color y la técnica, defendiendo, además, el arte como creación y no como imitación. Por todo esto descalifica la gastada fórmula académica y el "exclusivo tema pintoresco" de los indigenistas.

Tanto Ríos como Pereira coinciden en ordenar la pintura peruana del siglo XIX y XX en tres etapas: el Academicismo, el Indigenismo y los Independientes; también en usar el aforismo de Denis para aludir al "problema plástico". Crean además una falsa dicotomía al asegurar que los pintores indigenistas privilegiaron el tema en desmedro de los valores plásticos. Por otro lado, Ríos utiliza una subcategoría que denomina "indigenismo independiente" para incluir en ella a artistas no vinculados con la Escuela Nacional de Bellas Artes y Sabogal.

4 Francotirador, según el DRAE tiene tres acepciones: "Combatiente que no pertenece al ejército regular.//2. Persona aislada que, apostada, ataca con armas de fuego. // 3. Persona que actúa aisladamente y por su cuenta en cualquier actividad sin observar la disciplina del grupo. 
En sus conclusiones, Pereira se plantea la pregunta “iExiste una pintura peruana?" $Y$ la respuesta es negativa, porque según él, se ha dado más énfasis al tema que a la pintura, es decir a lo social, al hombre y paisaje indígenas, descuidando la técnica y el color, que son los valores propugnados por la modernidad. Y para esto "hace falta una necesaria occidentalización" (...) "Necesita el Perú comprender, captar y aprender la técnica pictórica". (...) "Sumergirse en esta pintura europea (...) para poder expresar mejor después la vida del Perú y crear sus posibilidades artísticas". Por estas líneas se ve claramente que Pereira no amaba la pintura indigenista y menos a Sabogal, su defensor; en cambio se alinea con el grupo de Independientes que privilegia "los valores plásticos” y asume como maestro a Ricardo Grau.

Pero el trabajo de Pereira no puede ocultar cierta flojedad conceptual que, en cambio trata de hacer más sólida Juan Ríos en su

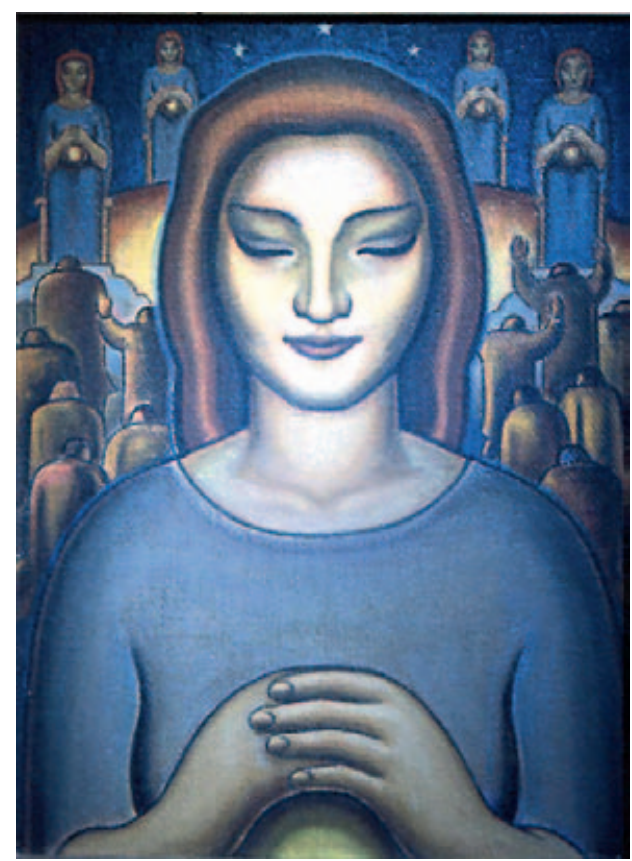

Urania. C. Quizpez Asín, 1930. (APSAV. propuesta de 1946, aunque más ambiciosa, ya que comienza definiendo lo que es la pintura: "Podría definirse la Pintura como el Arte de interpretar, por medio del color y la línea, las diversas emociones y sensaciones, objetivas y subjetivas, producidas por la visión de la naturaleza, de las cosas y los seres. Es decir: la creación de un equivalente plástico”. El equivalente plástico es el punto de partida para llegar más tarde a la reivindicación de "la significación específicamente plástica de la Pintura" . Ríos entusiasmado por el aparente radicalismo del aforismo de Denis se lanza a afirmar: "sólo por sus cualidades estéticas adquiere una tela, o un fresco, su categoría de obra de arte”. El asunto, la imitación, o el mensaje del artista, "No constituyen, en sí, los elementos básicos de la Belleza Pictórica”. Hasta aquí podemos, o no, estar de acuerdo con el crítico peruano; pero cuando concluye diciendo que la determinación de la belleza plástica, como la poética o la musical, "pertenece al dominio de lo inefable", sentimos un gran desconcierto. Claro, en lo inefable se esconde todo lo que ignoramos.

Es tan rotunda la afirmación que trato de buscar una explicación. Creo que Ríos, y también Pereira, hacen una interpretación errada del aforismo de Denis que los lleva a creer que el pintor y teórico francés rechaza el tema, las ideas, a favor de la pintura-pintura y lo concreto del color. Tienden a separar aquello que tradicionalmente es un todo. Esto me hace pensar que ni Ríos, ni Pereira, conocían la pintura de Denis, que desdice la letra de su aforismo, ya que es un llamado a la espiritualidad cristiana sazonada con elementos decorativos. Su pintura, en suma, se postula contra la sensorialidad del impresionismo.

Tanto Ríos como Pereira, que han esgrimido argumentos estéticos tomados del teórico francés con la finalidad de independizar a la pintura peruana del lastre nacionalista, caen en contradicción al tocar el tema de La Escuela Peruana. Dice Ríos: "en el Perú no existe todavía una Escuela Nacional de Pintura. Carente de conocimientos técnicos superiores, haciendo del tema el elemento primordial y distintivo de su estética, el grupo Indigenista que preside Sabogal no supera, en la mayoría de sus cuadros, el estadio del folklore o de la

5 Ríos, Juan, La pintura contemporánea en el Perú, Lima, Cultura Antártica, 1946, p.50 


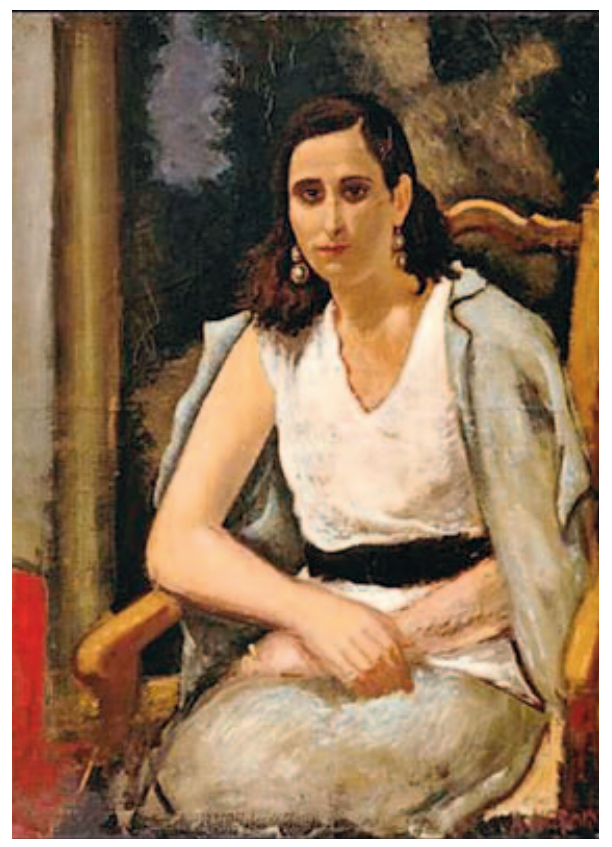

Retrato. Dubois de la Petelliere. Fue sin duda el pintor francés que más influyó en Grau en la época que estudió en París.

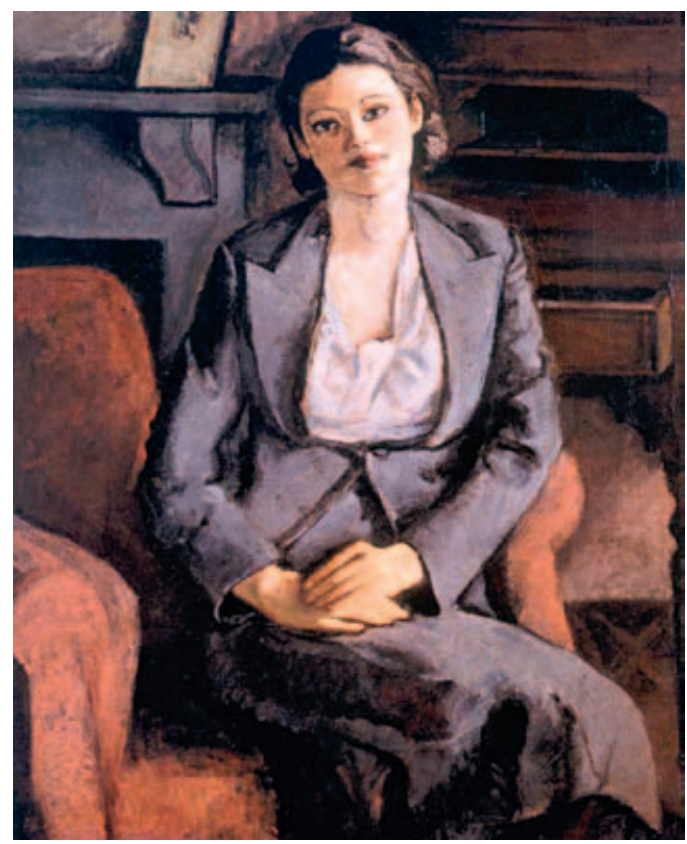

Retrato de Iris Grau. Ricardo Grau. Óleo sobre tela, ca. 1938. (C) APSAV.

ilustración costumbrista". ${ }^{6}$ Y concluye afirmando que el grupo indigenista está "al margen de las inquietudes esenciales de la Estética”. Me pregunto ¿de qué Estética? La europea por supuesto.

Este programa se cierra con una declaración pesimista: "De lo expresado se deduce que la situación del Arte en el Perú es de las más lamentables..." Y, de acuerdo con Marx y el Materialismo Histórico, termina diciendo que en un país como el nuestro, "agrario y semicolonial dominado por grandes latifundistas", donde no existe proletariado y la masa campesina es "esclavizada y analfabeta" (...) "La pintura no encuentra clima propicio".7

Ríos les negó valor a Sabogal y a los indigenistas porque rechazaron "las necesarias enseñanzas del Arte Occidental" y porque no traslucían el "espíritu de nuestro tiempo", sin comprender que su propuesta significaba otro tipo de pintura, quizás más pegada al expresionismo rústico, por sus colores y los soportes de yute que empleaban, inseparables del tema que mostraba, sin cohibirse, el mundo andino con su belleza y su fealdad. El movimiento respondió al espíritu de su tiempo, a las luchas sociales de los años 20, pero Ríos y Pereira no tuvieron ojos para verlo.

El rechazo del Indigenismo por Ríos es comprensible, pero su ceguera, inexcusable. Si el aforismo de Denis fue su ideal se entiende que no conoció pintura más allá del simbolismo, como los expresionismos tanto francés como alemán; o no le interesaban. En las líneas introductorias al capítulo sobre el Indigenismo, Ríos avanza lleno de prejuicios y contradicciones tratando de medir la bondad de las obras del grupo con el metro simbolista expresado en el aforismo de Denis. "Un imperfecto oficio", "grosero dibujo", "rudimentaria composición”, "turbio empaste”, son los calificativos que atribuye a la pintura del grupo creado por Sabogal. 
Con estos conceptos trata Ríos de caracterizar a Sabogal, Codesido, Camilo Blas, Teresa Carvallo, Camino Brent y Ricardo Flores, y como sólo tiene presente los modelos europeos, no ve algunos aspectos que son relevantes en, por ejemplo, la pintura de Camilo Blas. Este pintor, a parte de los justos reconocimientos de la crítica actual ${ }^{8}$, fue un refinado colorista que trabajó con eficacia las gamas de secundarios logrando esas atmósferas mates y apasteladas que han hecho de su pintura una excepción en el grupo indigenista. Qué injustas suenan hoy día las palabras que Ríos le dedica: "La obra de Camilo Blas es,

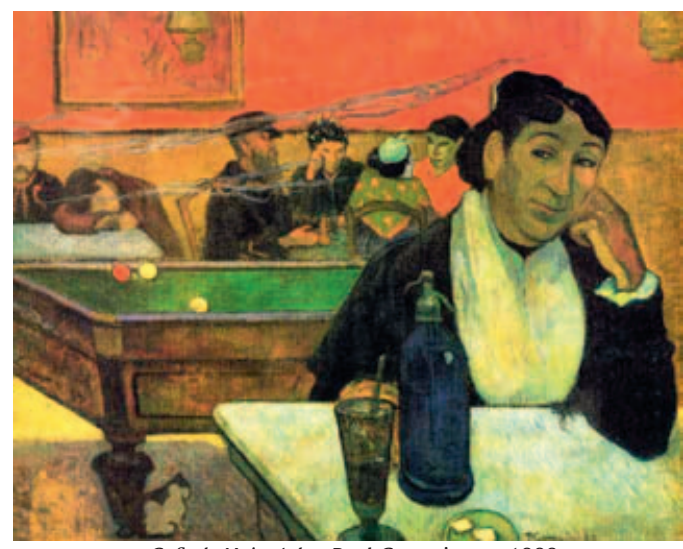

Cafe de Nuit, Arles. Paul Gauguin, ca. 1888. Óleo sobre tela, $72 \times 92 \mathrm{~cm}$.

acaso, la que más sometida se encuentra a la búsqueda del tema y del color local ${ }^{9}$; y, por lo mismo, la más carente de valores esencialmente plásticos. Algunas veces su delectación por lo pintoresco lo aproxima más de lo deseable a la caricatura iluminada. Su gama es vistosa, su composición movida y rudimentaria, su empaste pobre y sus contornos rápidos y nerviosos". Juicios demasiado subjetivos que hacen pensar dos cosas: la animadversión de Ríos al grupo o su estrecha visión estética.

Así pues, descalificados la Academia y el "estrecho canon Indigenista”, no quedaba en el Perú sino una tercera opción: los Independientes. Este grupo, conformado en su mayoría por artistas pertenecientes a la Sociedad de Bellas Artes, expuso por primera vez en 1937, sin constituirse como tendencia, ni publicar ningún manifiesto. Practicaban la democracia artística y, siguiendo el ejemplo de sus homónimos parisinos, cualquier ciudadano podía participar. Se podría pensar que, haciendo honor a su nombre, desterrarían de la exposición todo asomo de indigenismo, pero no fue así: el 50\% de los expositores adherían todavía al nativismo instaurado por Sabogal. Sin embargo se podía ubicar, contando con los dedos de una mano, a algunos pintores que se distinguían por la libertad con que trataban sus temas, donde se percibía un aire de modernidad y los ecos de lo aprendido en Europa. "Pertenecen, a esta (tercera categoría), todos aquellos que, con diversos grados de fidelidad, siguen la definitiva consigna de Maurice Denis y Paul Serusier", Macedonio de la Torre, Carlos Quípez Asín, Ricardo Grau, Federico Reinoso, Sabino Springett y Juan Manuel de la Colina. Todos ellos alcanzan -según Ríos- "un valor plástico muy superior al indigenista" pero, sin embargo, adolecen de "sello propio" y carácter nacional.

Naturalmente, el pintor que colmaba los deseos de Ríos y Pereira de una nueva pintura en el Perú, que dejara de lado el tema a favor de los "valores plásticos", era Ricardo Grau, que llega a Lima en 1937, justo el año de la inauguración de los Independientes.

El entusiasmo de ambos críticos los hace propagandistas de este adviento. Ríos dice: "Ricardo Grau ha sido, en el Perú del siglo XX, el artista encargado de "abrir las ventanas",

8 “capacidad de estilización", sintetismo extremo, "inagotable versatilidad", "mirada permanentemente alerta a lo que sucedía alrededor”, en: Natalia Majluf, L.E. Wuffarden, Camilo Blas, Museo de Arte de Lima, Lima 2010 .

9 En la tradición académica se distingue entre "color propio" y "color local". "El primero es el de base o específico de un objeto; el segundo representa las variaciones y modificaciones del color propio en la perspectiva aérea o de color" "El color propio de cada objeto se debilita en razón de la distancia y a esta disminución contribuye el aire interpuesto: Este es el verdadero color local, dice F. Milizia en su Dizionario delle Belle Arti del Disegno" , 1797. Grassi e Pepe, Dizionario Della Crítica d'Arte, UTET, Torino, 1978, vol. I, p. 110. En su texto Ríos usa "color local” en otro sentido, como colorido popular, folclórico, diverso al color "culto" o académico. 


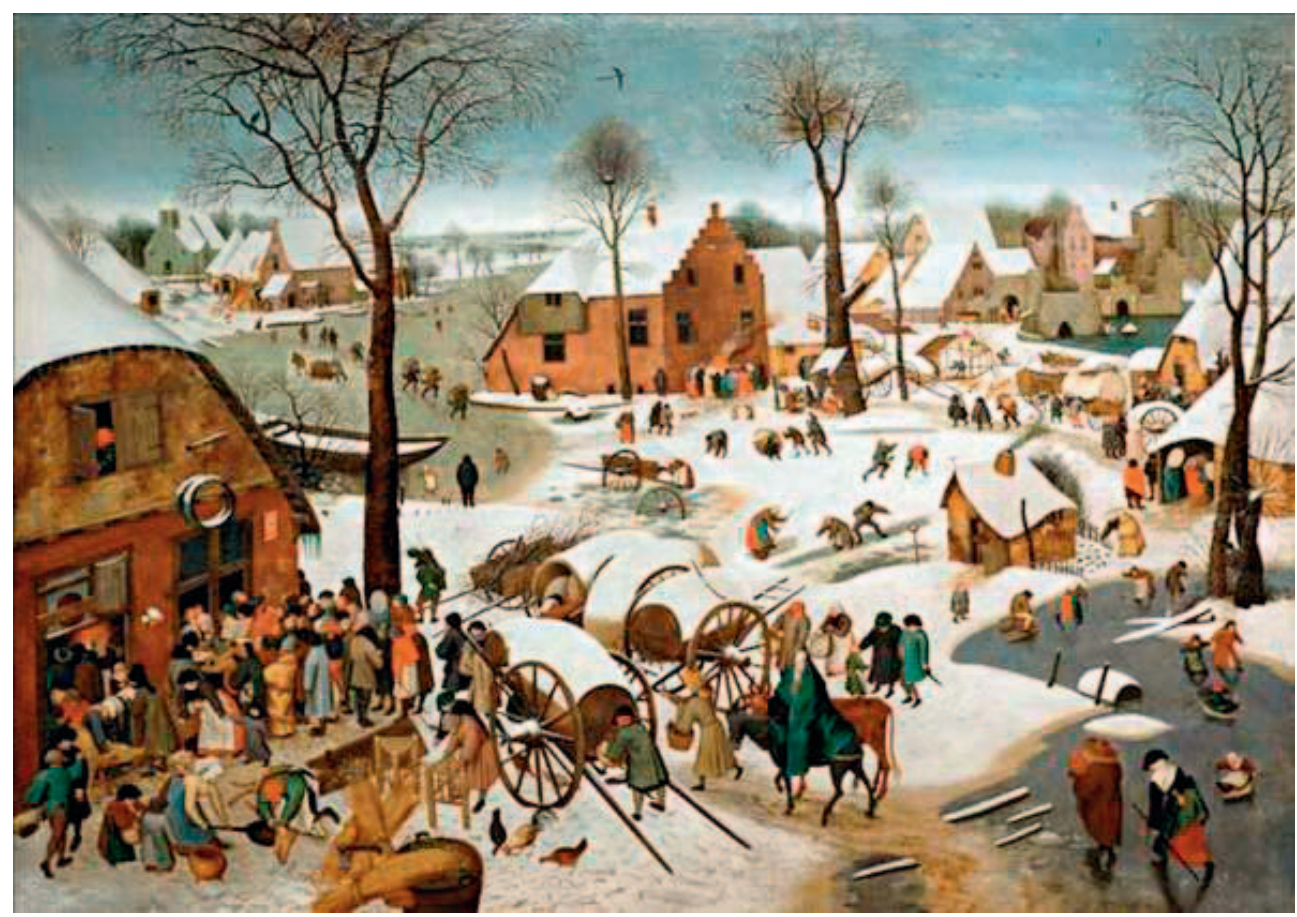

La llegada a Belén. Bruegel el Viejo, 1566.

de reivindicar la significación específicamente plástica de la Pintura”. (...) (Grau) "Es, probablemente, de todos los pintores del Perú, el que mejor obedece a la estricta definición de Denis y Serusier". Pereira no se queda atrás: "La dirección dada por sus maestros, el contacto directo con las corrientes modernas y los museos europeos, el ambiente en una palabra, han impreso a su obra un carácter estrictamente occidental, francés, propio de la escuela de París en la que predomina el valor exclusivamente pictórico por encima de las necesidades circunstanciales de tema o argumento".

El libro de Ríos y el artículo de Pereira sirvieron de fuentes de consulta obligada de estudiosos y aficionados en los años 40 . Si bien sirvió para poner en evidencia el arte contemporáneo y hacer ver al público algo diferente a lo que se conocía de la pintura de los maestros del XIX, creó ciertos equívocos respecto al estilo de algunos de nuestros pintores, como el caso de Carlos Quizpez Asín y su "anemia cromática”. Ríos dedica una pequeña nota donde dice: "Su estilo falto casi siempre de emoción vital y de pujanza colorista, es, en tales casos (se refiere a los murales), sobrio y decorativo, no carente de equilibradas cualidades arquitectónicas. En el lienzo, su Pintura, no obstante la geométrica armonía de su dibujo y su innato sentido del ritmo, adolece de frío esquematismo y de anemia cromática".

Ríos demuestra una manía por hacer comparaciones fuera de contexto que resultan exageradas. Cuando comenta la pintura de Macedonio dice que sus cuadros nos recuerdan "la nerviosa inspiración de Van Gogh" o cuando habla de Vinatea lo llama "el Brueghel del Perú". Quiero pensar que la referencia al pintor flamenco no tiene que ver con su estilo sino más bien con el contenido: tanto Brueghel como Vinatea se identificaron con el hombre y con la tierra, sin embargo son dos pintores completamente distintos. Al comentar la primera época de Sabogal "acusa la influencia de Zuloaga” y echa mano de Gauguin para explicar su segundo período de paleta más clara. Ambas son comparaciones poco afortunadas por lo lejos que están de los pintores citados. 
Ríos usa una subcategoría que denomina "Indigenistas independientes" caracterizados por "un conocimiento técnico mayor" y "una más amplia libertad frente al tema, reducido a su modesta función de trampolín estético". Los temas de Vinatea no son solamente un pretexto estético. Como los de Camilo Blas presentan, básicamente, la vida del hombre andino, el trabajo en el campo, el comercio en los mercados, el ir y venir de las balsas en el lago. Sin embargo de éste dice que su pintura colinda con la "caricatura iluminada", sin darse cuenta que son dos maneras distintas de pintar. En Ríos prima un prejuicio insalvable que no le permite comprender propuestas fuera del esquema de los "valores plásticos". Por otro lado, podemos asegurar que tanto Vinatea como Camilo Blas no separaban el tema de lo meramente plástico, sino que los consideraban una misma cosa.

Juan Ríos comienza su nota sobre Vinatea Reinoso con un juego de palabras que en lugar de aportar una explicación sobre la pintura del artista arequipeño, la complica al extremo de hacerla incomprensible. Dice: "Jorge Vinatea Reinoso estaba dotado del sentido pictórico de lo pintoresco, es decir: justamente lo contrario del sentido pintoresco de lo pictórico que constituye el error obstinado de Sabogal y sus discípulos". Traducido significa que Vinatea tenía más sensibilidad pictórica (de acuerdo a la teoría de los "valores plásticos") para plasmar los temas pintorescos (es decir vernáculos) que Sabogal. Pero depende del significado que Ríos le dio a la palabra "pintoresco" en su retruécano. El concepto de pintoresco (Pittoresco $)^{10}$, tal como se presenta en la historiografía occidental, se oponía al arte académico, como una categoría o género no menos importante. Ríos asigna al Indigenismo el valor de pintoresco, no como una alternativa a la pintura académica, de acuerdo a la tradición occidental, sino como una pintura temática, de tesis, o también folklórica, contraria al "sentido pictórico" por él propugnado. Por eso -según Ríos- Vinatea está dotado de sentido pictórico (ritmo lineal e interno, armonía cromática) que va "más allá del asunto" y su obra tiene esa "calidad esencial y perdurable". ${ }^{11}$

Otro caso de interpretación distinta de un término utilizado por la crítica de arte occidental y adaptado al caso peruano es el de "pompier"12, utilizado por Pereira para caracterizar la pintura de González Gamarra, a quien le corresponde, en cambio, el de "incaísta”.

Podríamos decir para concluir que tanto Ríos como Pereira coinciden en ordenar la pintura peruana del siglo XIX y XX en tres etapas: el Academicismo, el Indigenismo y los Independientes; también en usar el aforismo de Denis para aludir al "problema plástico". Por otro lado, Ríos utiliza una subcategoría que denomina "indigenismo independiente" para incluir en ella a artistas no vinculados con la Escuela Nacional de Bellas Artes y Sabogal.

Desde el punto de vista de la crítica de arte, que aquí nos ocupa, el planteamiento de Ríos y Pereira llevó a un error conceptual al crear la falsa dicotomía del tema vs. forma que desfavorecía a los indigenistas haciendo pensar que privilegiaban elementos extra artísticos como la literatura o la política. Abrió equívoca e innecesariamente dos campos, el de los "pictoricistas" y el de los "temáticos", porque, para la pintura figurativa que se practicaba en los años 40, el tema y la forma eran una misma cosa. El tema de los Indigenistas es el hombre andino, su trabajo y sus costumbres; el tema de los Independientes los retratos del hombre de la capital, bodegones, desnudos, sus fantasías...Los temas de los dos grupos,

10 Pintoresco, (Pittoresco) Opuesto al concepto de "belleza” clásica (simetría, equilibrio, etc.), afín a las formas irregulares, intrincadas, relacionado sobre todo con el paisaje con árboles enormes, precipicios, montañas, cavernas, cielos tempestuosos y ruinas, como en las pinturas de Salvatore Rosa". Grassi y Pepe, Dizionario de la crítica d'arte, vol. II, p. 407 y ss.

11 Ríos, Juan, Op. cit, p. 58.

12 Estilo Pompier: "Definición con la que vienen indicadas, en sentido despreciativo, obras figurativas (...) que responden a los cánones de un realismo académico y ecléctico, privadas de una intrínseca validez. (...) Se ha puesto en evidencia las relaciones entre el estilo Pompier y el fenómeno del kitsch". Grassi e Pepe, Dizionario Della crítica d'arte, UTET, Torino, 1978, vol. II, p. 418. 


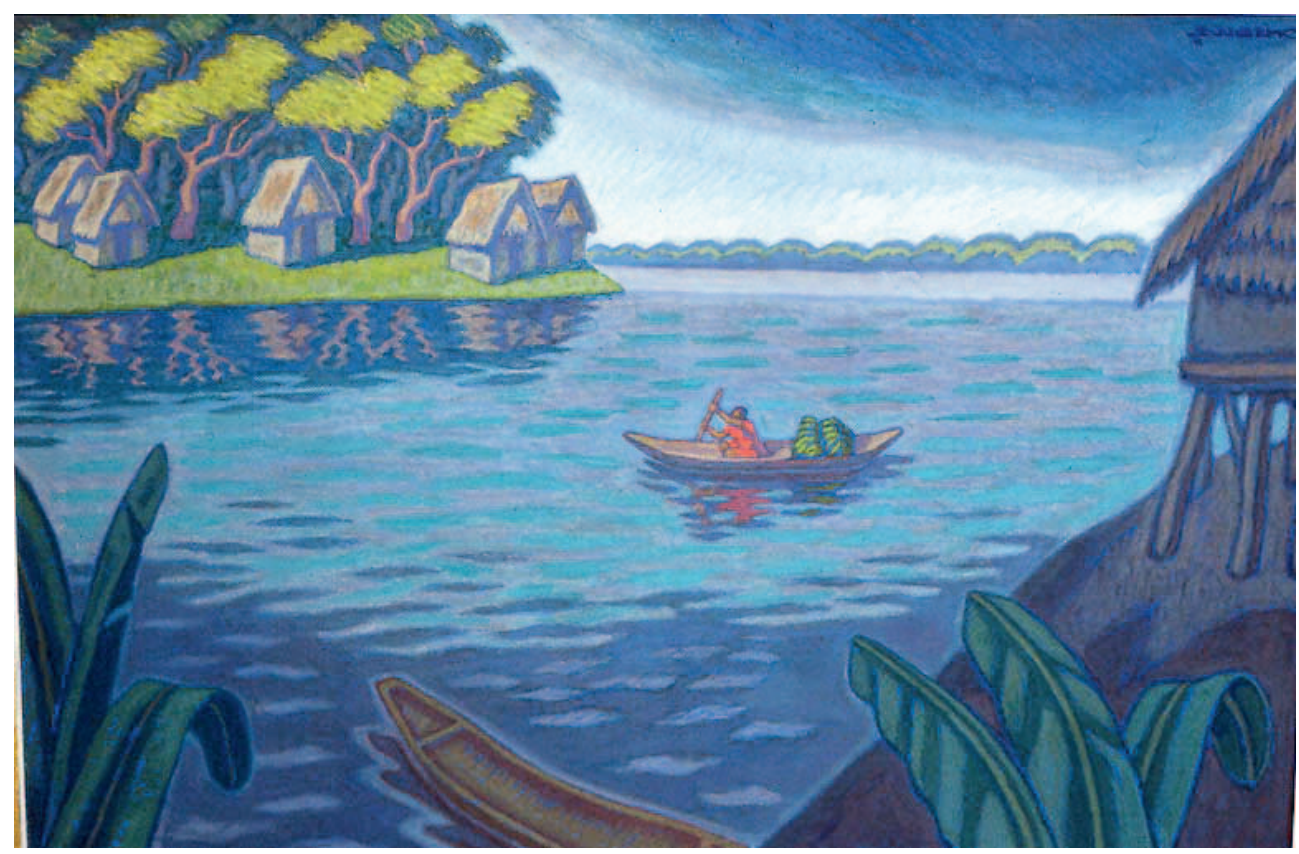

Río selvático. Camilo Blas.

en última instancia, conciernen al hombre y para el hombre peruano y, si hay una diferencia se la debe buscar en el gusto y el estatus social de quien pinta y para quién pinta.

Los trabajos de Ríos y Pereira llegan hasta el año 46. En el 47 surge el grupo Espacio que apoyó y favoreció a los primeros pintores abstractos de Lima. A partir de entonces, dado el desarrollo que emprenderá el arte en el Perú, el aforismo de Maurice Denis no se usará para convencer a nadie, se lo echa al olvido. Pero, desde esa región imprecisa y opaca, sin proponérselo, comenzará a tener sentido, y al convertirse la figuración en cenizas, adicionando baldazos de color, nacerá el concretismo estadounidense de los años 50 y más tarde el experimento expresionista abstracto en nuestra capital. 